\title{
Space Charge Criteria on Materials for HVDC: Assessment of Materials from Different Crosslinking Routes
}

\author{
G. Teyssedre ${ }^{1 *}$, T.T.N. Vu ${ }^{2}$, I. Denizet ${ }^{3}$, J.C. Gard ${ }^{3}$, S. Le Roy ${ }^{1}$, C. Laurent $^{1}$, M. Mammeri ${ }^{3}$ \\ ${ }^{1}$ Laplace, Université de Toulouse, CNRS, UPS, INPT, 118 route de Narbonne, F-31062 Toulouse Cedex 9, France; \\ ${ }^{2}$ Electric Power University, 235 Hoang Quoc Viet, Hanoi, Vietnam \\ ${ }^{3}$ SilecCable, rue de Varennes Prolongée, 77876 Montereau Cedex
}

\begin{abstract}
Among essential issues for HVDC cable is the field distribution inside the insulation resulting from combined processes of temperature gradient in the cables, non-linear conductivity and space charge accumulation. The assessment of materials in terms of conductivity is relatively straightforward based on its dependence upon temperature and field. In terms of space charges, the exploitation of data is more debatable as not only quantitative features but also the dynamics of processed is to be analyzed. In this work we illustrate such an analysis considering space charge results obtained on materials crosslinked by different ways. The work points to the need to limit by-product contents in HVDC cable materials.
\end{abstract}

\section{INTRODUCTION}

Substantial progresses have been made over the last years for developing new grade of polyethylene materials for the insulation of HV cables under DC. Among essential issues for the extension of HVAC cables technologies to HVDC stress is the field distribution inside the insulation resulting from combined processes of temperature gradient in the cables, non-linear conductivity and space charge accumulation. The field distribution can evolve in time owing to the slow transient nature of the response of materials under DC, to possible evolution of the concentration of residues in the cable, and to possible aging effects, as ranked by increasing order of time scale.

If solely conductivity is considered, and evolution of materials in time is neglected, then the field distribution is in principle predictable at any time under a given voltagetemperature stress cycle. The requirements are the geometry of the system, accurate measurement data on the materials properties related to the temperature and field dependence of the conductivity, along with some other features like thermal properties and permittivity. Therefore, targets can be identified as good or bad materials regarding conductivity behavior [1]. The question of space charge accumulation is not that straightforward to address. First, data collected are timedependent space charge density profiles under voltage or short circuit, with different types of carriers. Second, the dynamic behavior of the stored charge in time has to be appreciated and compared for assessment purpose [2]. In the following, the behavior of space charges under polarity reversal is addressed and the way these features should be analyzed is discussed. We illustrate the analysis considering space charge results obtained on materials crosslinked by different ways: traditional peroxide crosslinking and crosslinking process enhanced using co-agents of reaction.

\section{Methodology}

\section{A. Materials}

Rough products were cross-linkable low density polyethylene -LDPE in the form of granules (material A). Three kinds of materials are considered here. Two of them are commercial AC (material B) and DC grade LDPE (C), containing peroxide. Material $\mathrm{D}$ was crosslinked using an alternative route. Compared to standard crosslinking of polyethylene, it consists in incorporating co-agents of reticulation with allylic functions, which are well known in the field of elastomers crosslinking [3]. The crosslinking mechanism of $\mathrm{PE}$ in the presence of co-agents may be described as the result of the grafting reactions of the polymer and by reactions of homopolymerization of the co-agents molecules which will penetrate in the three dimensional network and strengthen the material, cf. Scheme 1. Details on the crosslinking process developed are given elsewhere [4]. Due to the strong reactivity of the co-agent, the amount of peroxide necessary to achieve crosslinking is less and the amount of by-products formed is very substantially reduced, whereas good crosslink density was obtained.

For all materials, plaques of LDPE were processed by pressmolding at $120^{\circ} \mathrm{C}$ and then crosslinked at $180^{\circ} \mathrm{C}$ for $15 \mathrm{~min}$. Final samples were disks of $500 \mu \mathrm{m}$ thickness and $80 \mathrm{~mm}$ diameter. Samples B and $\mathrm{C}$ were degassed, at $50{ }^{\circ} \mathrm{C}$ for 2 days Gold electrodes of $10 \mathrm{~mm}$ diameter were deposited by sputtering process.

\section{B. Space charge measurements}

Space charge measurements were realized using the pulsed electro-acoustic -PEA method. The typical test procedure is depicted in Fig. 1, consisting in polarization/depolarization at
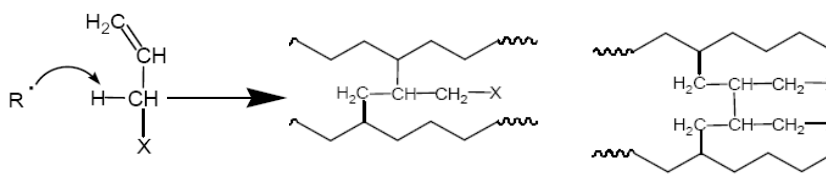

Scheme 1. Co-agent aided crosslinking 
$-10,-20,-30 \mathrm{kV} / \mathrm{mm}$, each step lasting $3 \mathrm{~h}$, up to $-40 \mathrm{kV} / \mathrm{mm}$ step followed by polarity inversion to $+40 \mathrm{kV} / \mathrm{mm}$ lasting for $3 \mathrm{~h}$, and finally depolarization measurement for $3 \mathrm{~h}$. Applied field ramps-up and ramps-down were $1 \mathrm{kV} / \mathrm{mm} / \mathrm{s}$. Cycles of $3 \mathrm{~h} / 3 \mathrm{~h}$ polarization/depolarization were chosen as a compromise between a quasi-steady state behavior and reasonable measurement time. The PEA test cell was installed in an oven; all measurements were achieved at $40^{\circ} \mathrm{C}$.

\section{Space charge criteria}

Space charge build-up in insulations has two consequences, first the distortion of the electric field, with necessarily some strengthening of the field at some place of the dielectric, and second charge movement, which can be fast and can produce damage with fast voltage variation, such as breakdown at grounding. The effect of field strengthening can be related to the lifetime through the well-known Inverse Power Law -a semi-empirical relationship giving the time to breakdown as a function of the maximum stress level through the insulation:

$$
L=C .\left(\frac{1}{F_{\max }}\right)^{N}
$$

where $\mathrm{F}_{\max }$ accounts for the maximum electrical stress through the insulating material, $\mathrm{N}$ is the aging parameter also known as the Voltage Endurance Coefficient (VEC) and $\mathrm{C}$ is a constant. A first criterion issued from space charge results is the field enhancement factor-FEF representing the maximum value in local field divided by the geometric field. In case of polarity inversion, it has been demonstrated [5] through accelerated life tests coupled to space charge measurements that the insulation life depends not only on the electrical stress level but also on parameters such as the quantity of charge $\left(\mathrm{Q}_{\mathrm{M}}\right)$ obtained after polarization under an applied field $\mathrm{F}_{\mathrm{app}}$, the charge depletion rate during depolarization (s) and the frequency of polarity inversion (f). According to the model proposed by Cavallini et al [6], the ratio between life with $\left(\mathrm{L}_{\mathrm{I}}\right)$ and without $(\mathrm{L})$ voltage inversion is given by:

$$
\frac{L_{I}}{L}=\frac{1}{1+K \cdot s^{-a_{1}} Q_{M}\left(F_{a p p}\right) \cdot f^{a_{2}}}
$$

where $\mathrm{K}, \mathrm{a}_{1}$ and $\mathrm{a}_{2}$ are correlation coefficients.

According to Eq. (2), the insulation life decreases with the frequency of inversion and the amount of trapped charge $\left(\mathrm{Q}_{\mathrm{M}}\right)$. For polymeric materials, $\mathrm{Q}_{\mathrm{M}}$ is generally assumed to evolve as a power function of the applied field $\mathrm{F}_{\text {app }}[19,20]$ for electrical stresses above the ohmic regime. The insulation life in the presence of inversions $\left(\mathrm{L}_{\mathrm{I}}\right)$ decreases inversely with the charge depletion rate. It means that in the presence of inversion, the material should be able to expel trapped charges as fast as possible during short-circuit. Hence, deep traps introduced by chemical additives within the insulating material may be harmful with regard to the material endurance.

For comparative analysis of case studies (i.e. XLPE), it will be assumed that the correlation coefficients $\left(K, a_{1}\right.$ and $\left.a_{2}\right)$ involved in the expression of the insulation life are not modified by varying the material process condition. Only the

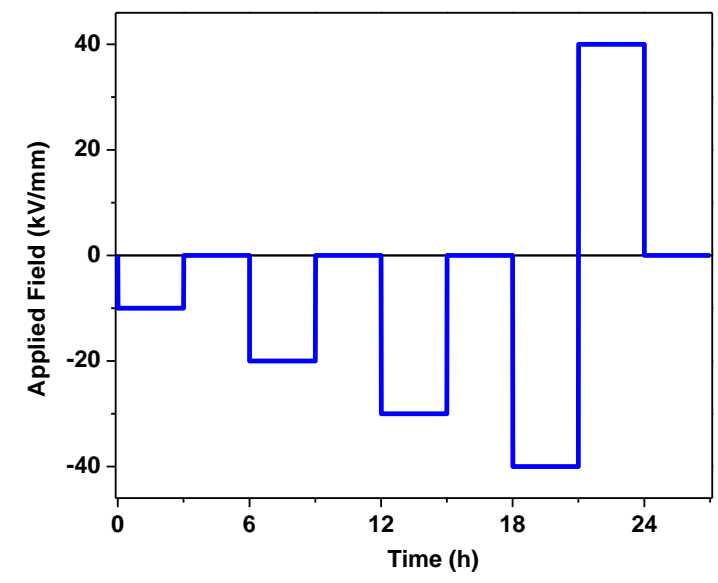

Fig. 1. Stress cycle applied for space charge measurements on flat specimens.

parameters related to space charges that are the field enhancement factor, the trapped charges density and the depletion rate during volt-off are modified. These 'Quality' parameters were derived using space charge data:

- the space-averaged space charge distribution determined by:

$$
Q_{M}(t)=\frac{1}{d} \int_{0}^{d}|\rho(x, t)| d x
$$

where $\mathrm{d}$ is the inter-electrodes distance. The value, $\mathrm{Q}_{\mathrm{M} 0}$ estimated just after grounding is considered as the amount of accumulated charges during the volt-on procedure.

- the field distribution is obtained from the charge distribution; The value of the FEF and the evolution in time of the position where the FEF is at maximum are used. The maximum value of the FEF in every voltage step is used.

- parameters related to the traps (density, apparent depth in energy) can be extracted from the transient in space-averaged charge density decay using a proper detrapping model [7]. During the discharge, charges are supposed to be emitted, without retrapping, from a square-like trap distribution of density $\mathrm{N}_{0}$ per unit energy within a range of trap depths $\left[\Delta_{\min }-\right.$ $\left.\Delta_{\max }\right]$. Estimated quantities are $\Delta_{\min }, \Delta_{\max }$ and the charge resorption rate s, expressed in \% per decade in time [2]:

$$
s=\frac{1}{Q_{M 0}} \cdot \frac{d Q_{M}(t)}{d \log (t)}=\frac{-k_{B} T}{\Delta_{\max }-\Delta_{\min }} \ln (10)
$$

where $\mathrm{Q}_{\mathrm{M} 0}$ is the initial amount of charges. In the comparison of several formulations, assessment related to the space charge behavior assumes that the best formulation is the one which exhibits an optimized set of properties, say the lowest amount of charge density, the lowest FEF and the highest rate of charge release during volt-off.

\section{RESULTS AND DISCUSSION}

\section{A. Space charge patterns}

Fig. 2a shows the space charge patterns obtained on LDPE. A relatively small amount of charges is detected in LDPE with the current stressing conditions. These are essentially negative 


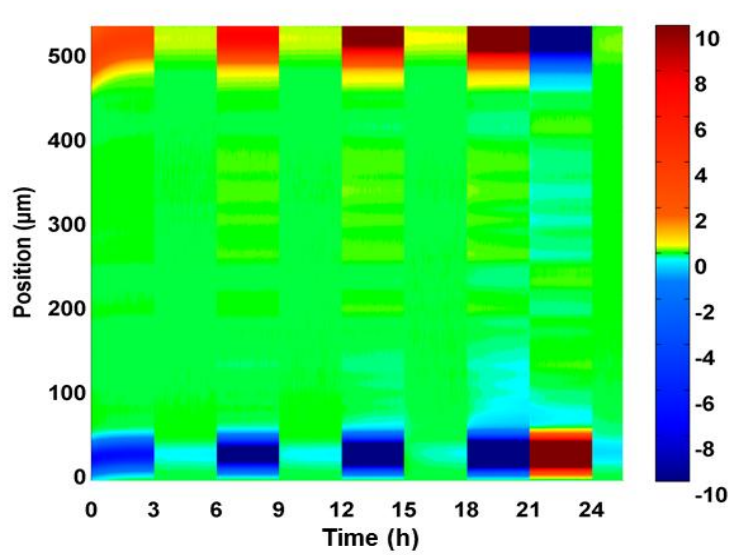

(a) LDPE-A

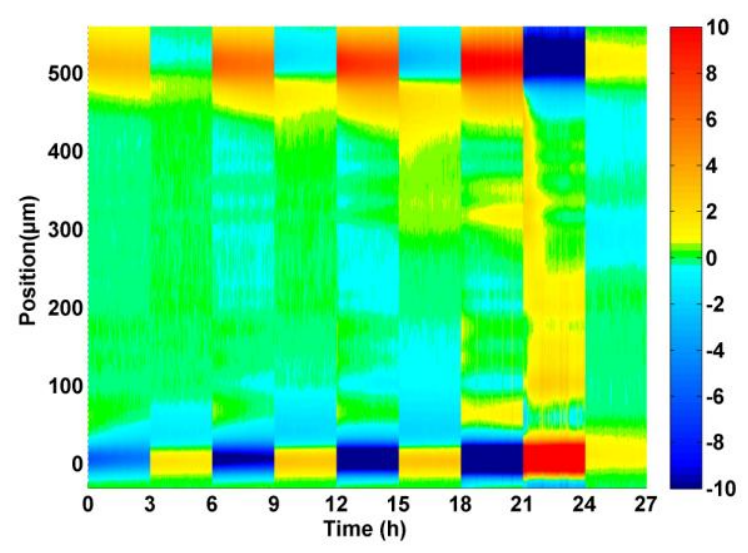

(c) XLPE-C

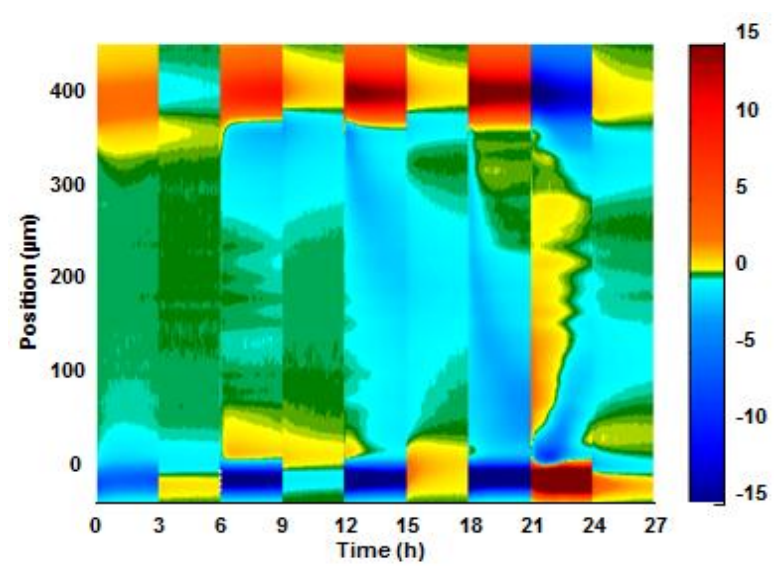

(b) XLPE-B

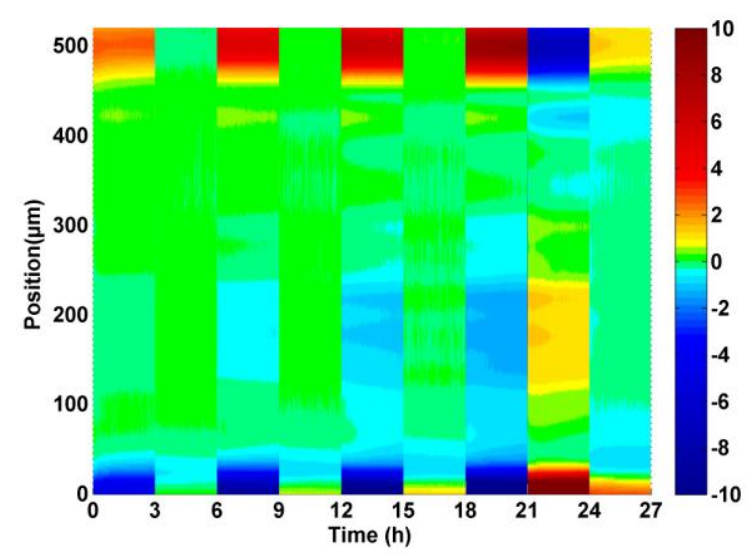

(d) XLPE-D

Fig. 2. Space charge patterns for the four specimens. The colour scale gives the space charge density in $\mathrm{C} / \mathrm{m}^{3}$

charges, still visible after the polarity reversal step. The residual charge density at the beginning of the Volt-off step is given in Table 1. It increases only slightly with the applied stress.

For commercial AC-XLPE, Fig. 2b, at low field (-10 $\mathrm{kV} / \mathrm{mm}$ ), charges are injected at both anode and cathode forming homocharges adjacent to the electrodes. A large fraction of these charges still remains after $3 \mathrm{~h}$ in Volt-off, suggesting the presence of deep traps within the bulk of the material. For higher stress level $(-20$ to $-40 \mathrm{kV} / \mathrm{mm})$, the bulk of the insulation is mainly dominated by negative charges that appear injected from the cathode and transported into the bulk. Negative charges enhance the field at the anode, triggering injection of positive charges as it can be seen at the beginning of the Volt-on step at $-40 \mathrm{kV} / \mathrm{mm}$. This phenomenon is even more spectacular after polarity reversal where positive charges are injected from the anode.

Patterns for XLPE-C and XLPE-D are substantially different compared to XLPE-B. The patterns in Fig. 2c and 2d obviously reveal less charges and are somewhat less complex. In XLPE-C, the charge switches from homocharge to heterocharge, depending on stress conditions, as if there were competition between injection and dissociation. Charges appear generated mainly by injection at the electrodes, with a nearly symmetrical density and position at low field and with positive charges dominating over negative ones at higher field. For XLPE-D (Fig. 2d), the charge tends to be negative before polarity reversal (as for LDPE). Positive charges appear next to the bottom electrode after inversion, presumably due to the field amplification resulting from to the previously stored negative charges. The residual charge densities after switching off the voltage are particularly low for XLPE-D, being of the order of $0.1 \mathrm{C} / \mathrm{m}^{3}$ for the first 3 levels of stress and of $0.3 \mathrm{C} / \mathrm{m}^{3}$ for the last one. Also, the FEF is low.

\section{B. Relative figures of merit}

Table 1 sum-ups data obtained for the different materials. The values of $\mathrm{FEF}_{\max }$ and $\mathrm{Q}_{\mathrm{M} 0}$ extracted for LDPE samples are pretty low. The maximum field distortion is less than $10 \%$ over the all cycle. We did not analyze the charge decay kinetics as the charge amount was too low to get appreciable results. We showed in [2] that when soaking LDPE samples into acetophenone, one of the crosslinking by-products, the amount of charge was considerably larger, by about 2 orders of magnitude. Acetophenone promotes the formation of negative heterocharges whatever the applied field, and with as consequence an increase in the local field by about 50\% in 
TABLE 1.

SUM-UP OF SPACE CHARGE DATA FOR TESTED INSUlATORS.

\begin{tabular}{|c|c|c|c|c|c|c|}
\hline \multicolumn{2}{|c|}{$\mathbf{F}_{\text {app }}(\mathbf{k V} / \mathbf{m m})$} & -10 & -20 & -30 & -40 & 40 \\
\hline \multirow{2}{*}{ LDPE-A } & $\mathrm{FEF}_{\text {max }}$ & 1.06 & 1.05 & 1.07 & 1.09 & 1.09 \\
\hline & $\mathrm{Q}_{\mathrm{M} 0}\left(\mathrm{C} / \mathrm{m}^{3}\right)$ & 0.08 & 0.08 & 0.12 & -- & 0.13 \\
\hline \multirow{4}{*}{$\begin{array}{c}\text { LDPE-A+ } \\
(1 \% \\
\text { acetophenone })\end{array}$} & $\mathrm{FEF}_{\text {max }}$ & 1.50 & 1.53 & 1.53 & 1.53 & 1.47 \\
\hline & $\mathrm{Q}_{\mathrm{M} 0}\left(\mathrm{C} / \mathrm{m}^{3}\right)$ & 0.25 & 0.63 & 0.97 & -- & 1.45 \\
\hline & $\Delta_{\min }(\mathrm{eV})$ & 1.04 & 1.00 & 0.92 & -- & 0.96 \\
\hline & $\Delta_{\max }(\mathrm{eV})$ & 1.14 & 1.14 & 1.13 & -- & 1.07 \\
\hline \multirow{4}{*}{$\begin{array}{c}\text { XLPE-B } \\
\text { (AC-XLPE, } \\
\text { peroxide, } \\
\text { outgassed) }\end{array}$} & $\mathrm{FEF}_{\text {max }}$ & 1.02 & 1.25 & 1.30 & 1.23 & 1.15 \\
\hline & $\mathrm{Q}_{\mathrm{M} 0}\left(\mathrm{C} / \mathrm{m}^{3}\right)$ & 0.13 & 0.52 & 0.78 & -- & 0.67 \\
\hline & $\Delta_{\min }(\mathrm{eV})$ & 1.02 & 0.98 & 0.97 & -- & 0.95 \\
\hline & $\Delta_{\text {max }}(\mathrm{eV})$ & 1.13 & 1.10 & 1.11 & -- & 1.11 \\
\hline \multirow{4}{*}{$\begin{array}{l}\text { XLPE-C } \\
\text { (peroxide, } \\
\text { outgassed) }\end{array}$} & $\mathrm{FEF}_{\max }$ & 1.10 & 1.13 & 1.10 & 1.05 & 1.15 \\
\hline & $\mathrm{Q}_{\mathrm{M} 0}\left(\mathrm{C} / \mathrm{m}^{3}\right)$ & 0.26 & 0.45 & 0.75 & -- & 0.35 \\
\hline & $\Delta_{\min }(\mathrm{eV})$ & 1.05 & 1.03 & 1.02 & -- & 1.05 \\
\hline & $\Delta_{\max }(\mathrm{eV})$ & 1.14 & 1.19 & 1.17 & -- & 1.13 \\
\hline \multirow{4}{*}{$\begin{array}{c}\text { XLPE-D } \\
\text { (without } \\
\text { by-products) }\end{array}$} & $\mathrm{FEF}_{\text {max }}$ & 1.07 & 1.05 & 1.05 & 1.06 & 1.02 \\
\hline & $\mathrm{Q}_{\mathrm{M} 0}\left(\mathrm{C} / \mathrm{m}^{3}\right)$ & 0.10 & 0.09 & 0.09 & -- & 0.33 \\
\hline & $\Delta_{\min }(\mathrm{eV})$ & 1.01 & 1.02 & 1.04 & -- & 1.03 \\
\hline & $\Delta_{\max }(\mathrm{eV})$ & 1.16 & 1.21 & 1.22 & -- & 1.17 \\
\hline
\end{tabular}

respect to the applied field [2]. The features appear consistent with earlier reports $[8,9]$.

The AC-grade XLPE (B) has really poor performances comparatively to the other two materials and the features support the efforts put along the years to develop crosslinked materials with improved properties in terms of space charge features [10]. Comparing features for XLPE-C and D, both the $\mathrm{FEF}_{\max }$ and the residual charge $\mathrm{Q}_{\mathrm{M} 0}$ appear lower for the latter before polarity inversion at $40 \mathrm{kV} / \mathrm{mm}$. Quantities approach here those obtained for LDPE. After polarity inversion, XLPE-D performs as well as XLPE-C. Only the charge dissipation rate, reflected by the value of $\Delta_{\max }$, is larger for XLPE-C, for all stress levels. The very fact that charge density is less might be one of the reasons for the slower charge release and hence larger apparent trap depth. Indeed, the residual field that controls charge transport is not taken into account in the detrapping kinetic model.

Overall, XLPE-D, which was crosslinked without byproducts, exhibits better performances. This is all the more remarkable that it was obtained without thermal conditioning of the material at $50^{\circ} \mathrm{C}$, which could also evacuate volatile residues like water. At the present time such alternative crosslinking scheme has not been transferred to the industrial scale. The degassing process consumes considerable amounts of energy. For instance, 43 days at $60{ }^{\circ} \mathrm{C}$ are required to remove $50 \%$ of the initial concentration of acetophenone contained in the middle of the insulation for a $18 \mathrm{~mm}$-thick XLPE insulated HV power cable [11]. Thus developing processes leading to less charge accumulation are highly desirable.

\section{CONCLUSIONS}

We have presented a methodology for assessing insulating materials for use in HVDC cables application from the standpoint of space charge characteristics. Materials figures of merit are defined in line with life models of insulations under DC stress, which encompass materials endurance under polarity reversal. Quantities of interest are maximum field distortion, residual charge density after DC stressing and parameters related to the kinetics of charge release. The use of such quantities, though resulting in a coarser picture of material response than space charge patterns may provide, has the advantage of permitting a direct material-to-material comparison, including comparison of materials association. Though the examples are given for flat specimen, in principle the procedure can be extended to cable geometry samples. Using this methodology, we confirm earlier reports on the detrimental effects of crosslinking by-products regarding space charge features and the promising aspects of processes limiting peroxide contents.

\section{REFERENCES}

[1] S. Boggs, H. Dwight, J. Hjerrild, J.T. Holbol and M. Henriksen, "Effect of insulation properties on the field grading of solid dielectric DC cable", IEEE Trans. Power Deliv., vol. 16, pp.456-462, 2001.

[2] T.T.N. Vu, G. Teyssedre, S. Le Roy and C. Laurent, "Space charge criteria for the assessment of insulation materials for HVDC", IEEE Trans. Dielectr. Electr. Insul. vol. 24, pp.1405-1415, 2017.

[3] J.W. Martin, "1,2 Polybutadiene resin co-agents for peroxide cure of rubber compounds", Rubber Chemistry and Technology, vol. 46, pp.275285, 1973.

[4] J.C. Gard, I. Denizet and M. Mammeri, "Development of a XLPE insulating with low peroxide by-products", Proc. 9th Int'l Conference on Insulated Power Cables (Jicable), pp. 1-5, 2015.

[5] G.C. Montanari and D. Fabiani, "Evaluation of dc insulation performance based on space-charge measurements and accelerated life tests", IEEE Trans. Dielectr. Electr. Insul., vol. 7, pp.322-328, 2000.

[6] A. Cavallini, D. Fabiani, G. Mazzanti and G.C. Montanari, "Life model based on space-charge quantities for HVDC polymeric cables subjected to voltage-polarity inversions", IEEE Trans. Dielectr. Electr. Insul., vol. 9, pp.514-523, 2002.

[7] L.A. Dissado, O. Paris, T. Ditchi, C. Alquie and J. Lewiner, "Space charge injection and extraction in high divergent fields," Proc. IEEE Conf. Electr. Insul. Dielectr. Phenom. (CEIDP), pp. 23-26, 1999.

[8] Y. Maeno, N. Hirai, Y. Ohki, T. Tanaka, M. Okashita and T. Maeno, "Effects of crosslinking byproducts on space charge formation in crosslinked polyethylene," IEEE Trans. Dielectr. Electr. Insul., vol. 12, pp.90-97, 2005.

[9] N. Hussin and G. Chen, "Analysis of space charge formation in LDPE in the presence of crosslinking byproducts", IEEE Trans. Dielectr. Electr. Insul., vol. 19, pp.126-133, 2012.

[10] T. Hjertberg, V. Englund, P.O. Hagstrand, W. Loyens, U. Nilsson and A. Smedberg, "Materials for HVDC cables", Revue Electricité Electronique, No. 4, pp. XI-XV, 2014.

[11] T. Andrews, R.N. Hampton, A. Smedberg, D. Wald, V. Waschk and W. Weissenberg, "The role of degassing in XLPE power cable manufacture", IEEE Electr. Insul. Mag., vol. 22, No. 6, pp.5-16, 2006. 